\title{
Scientific Interview: Tom Crowley (1948-2014)
}

\author{
Thomas Crowley from the University of Edinburgh, a pioneer in the field of paleoclimatology, passed away on May 8, \\ 2014. A few days before, he shared some retrospective thoughts on questions asked by his colleagues and friends, \\ Hans von Storch and Heinz Wanner. His wife Gabi Hegerl helped to edit the interview.
}

\begin{abstract}
Question: Tom, you are looking back on a long career in geosciences. Could you sketch your path and what attracted you to this field?
\end{abstract}

I started out as a marine geologist and had the good fortune to be involved in a project in the 1970s involving expanded exploration of the world oceans. The project leader was John Imbrie, a truly inspiring scientist. He developed a statistical methodology for converting assemblages of marine organisms into temperature, based on the observation that different types of plants and animals live in different temperature zones. This was formalized using regression methods and applied by the group CLIMAP (Climate: Long range Investigation, Mapping, and Prediction), whose purpose was to record the entire surface of the ocean during the last ice age so that climate modelers, who were just becoming known to the geologists, could test their models under radically different boundary conditions.

In my particular corner of the ocean, from the North Atlantic, East of the Grand Banks to the West coast of Africa, there was a distinct relationship between types of fauna and flora and the ocean currents. You could trace the Canary current, and the North Atlantic current just by looking at the distribution of the organisms. This got me interested in the question: What mechanisms might be invoked to infer changes in the past ocean circulation? It had already been known for almost 50 years that the Gulf Stream during the Last Glacial Maximum ( 20,000 yrs BP) flowed from West to East around $40^{\circ} \mathrm{N}$ rather than northward into the Northeast Atlantic. The question as to what would cause the ocean to do that was a big interest in my life and always fascinated me as a trigger point.

I was extremely fortunate to meet Jerry North, a modeler interested in applying energy balance models to past climates. When moving to Texas to work with Jerry we went out for Mexican lunches every day and expanded our energy balance work to supercontinents. This was a logical and satisfying application for energy balance models, because the land sea distribution

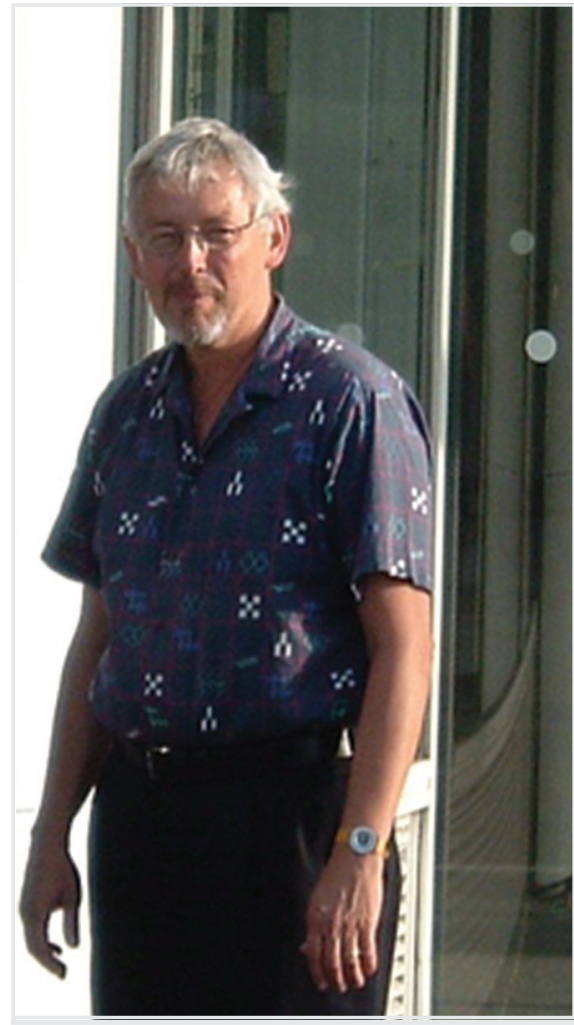

Figure 1: Tom Crowley (1948-2014)

primarily dominates the temperature response. I also brought in my background in Paleozoic geology. It seemed like the best of both worlds going into the past to explore things I knew about, and yet applying new techniques of climate modeling to better understand the great Paleozoic glaciations.

\section{Q: What was the most important twist to your career?}

I was very fortunate to receive an invitation from Klaus Hasselmann in Hamburg to visit their group and help to apply their ocean models to past climates. We looked at the Central American Isthmus, which had been open for several tens of millions of years before it closed, around the time when ice started to form in the northern hemisphere. We did some experiments opening and closing the Isthmus in order to explore the effect of its closure about three million years ago on global climate.
The closure of the Isthmus turned out to be an important event, and the model showed features that bore a lot of resemblance to the geological data. This launched a series of further studies with Ernst Maier-Reimer, Uwe Mikolajewicz and Christoph Heinze, in which we examined the effects of other "ocean gateway" changes such as the Drake Passage. It was very satisfying to be moving along two scientific fronts, learning about ancient climates and using a model that was also being applied for the first detection and attribution studies of modern climate change.

\section{Q: Your Science paper in $\mathbf{2 0 0 0}$ was a key publication for paleoscience. Was this your greatest scientific achievement?}

I started working on climate change over the last few centuries, because people were getting very interested in that topic. Over time a head of steam built up in terms of reconstructing climates and the climate forcing for those periods. I realized that many of the inferred climate changes could actually be reproduced very simply with an energy balance model, just by changing volcanism or solar variability. This result virtually fell into my lap and I was able to make an important, or at least a valuable contribution, being able to estimate how big the greenhouse gas signal was compared to solar or volcanically forced climate change and the Little Ice Age (LIA). By constraining the LIA climate change we could show that already in the $20^{\text {th }}$ century global warming was taking place at about the size it was expected to be from the forcing. This paper (Crowley 2000 ) is one I might be known more for than anything else. Yet it is not what I necessarily consider my most important contribution.

\section{Q: What then do you consider your most important scientific contribution?}

That was a little bit more arcane, involving the subject of Snowball Earth, which is an unusual period of time, about 600 million years ago when the earth was in a deep freeze, with ice on all land and maybe on all of the oceans too. The world was in a supercontinent configuration. The earth was at one of its most critical points with respect to the evolution of life. In my view the origin of life itself is not as important 

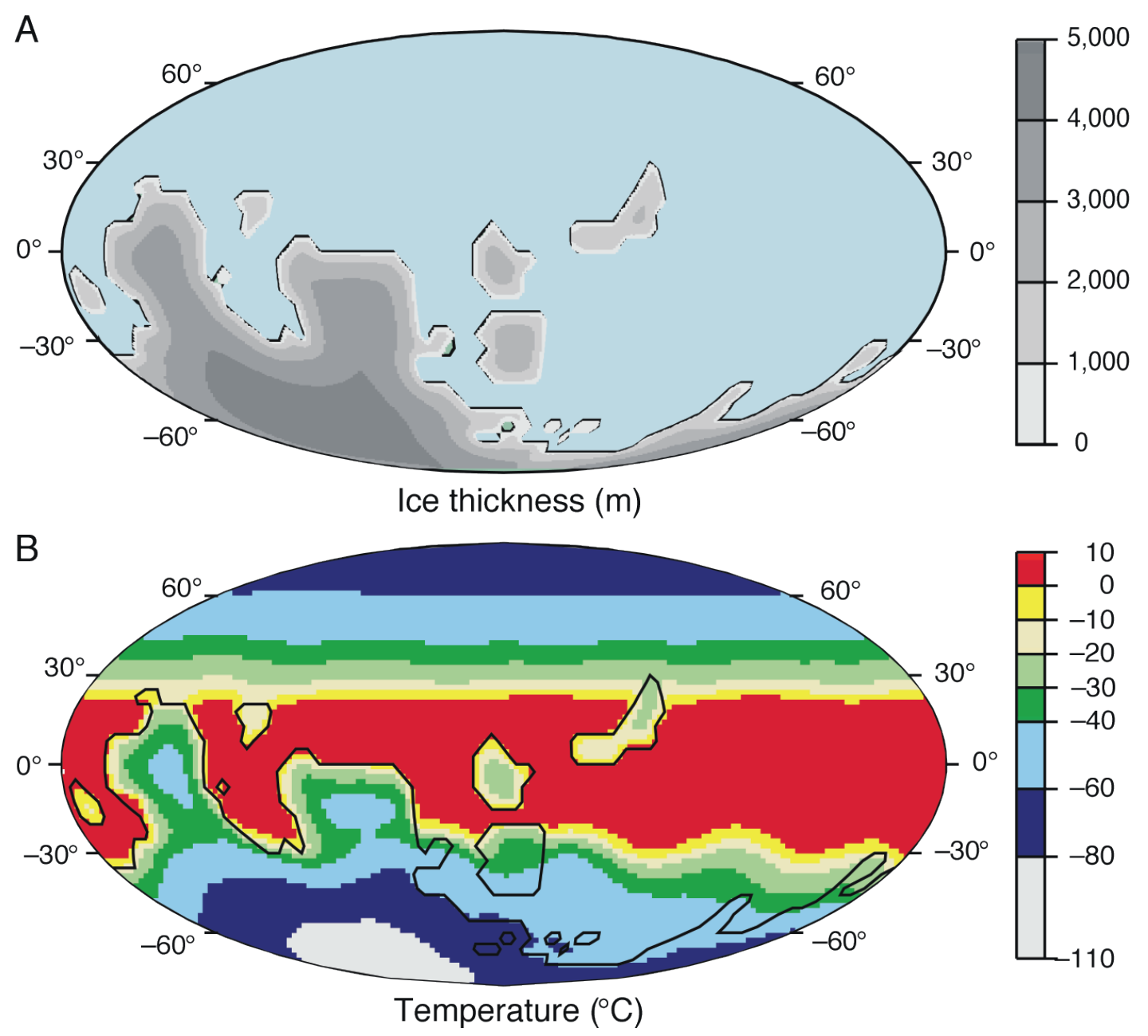

Figure 2: Tom Crowley's "most important scientific contribution". Late Precambrian (ca. 600 M yr BP) (A) ice cover and (B) temperature simulations. The annually average temperatures show that large areas of open water still might have existed while the continents were ice covered. The black lines represent the Precambrian landmasses. From Hyde et al. (2000).

as the evolution of multi-celled animals, which have a much narrower range of environmental restrictions. We knew that in order to study Snowball Earth properly we needed to couple an energy balance model to an ice sheet model. We got a grant from a very open minded NSF program director to allow us to explore Snowball Earth. We discovered that we could simulate a frozen-over earth fairly easily by just continuing to drop $\mathrm{CO}_{2}$. However, we realized that for one of our solutions we did get ice on land, but open water over parts of the ocean (Fig. 2). This indicated that maybe life was still frozen out on land, but had taken up an oasis in the open water area of the ocean that allowed it to breed successive generations of multi-celled intermediate organisms that provided the basis for the great explosion of life at the end of that period. We didn't claim this was the correct explanation, but it is a legitimate viewpoint that cannot be dismissed despite 14 years of criticism. I feel this paper (Hyde et al. $2000)$ is probably the most important thing that we ever did.

\section{Q: What is your judgment concerning the hiatus in the global temperature development of the last 15 years?}

This oscillation has all the markings of a natural fluctuation, maybe an El Niño imprint.
Extended-duration El Niños happen sometimes. However, I think the hiatus in global temperature has not quite been interpreted correctly. Based on my recent work that is just being published (Crowley et al. 2014), the system is now in a basic state that is more or less neutral, or maybe even in a little bit above average global temperatures for the last 15 years. So there may even be some statistical legitimacy for stating, not expecting, that temperatures could drop some $0.1-0.2^{\circ} \mathrm{C}$ for a few years. Of course temperature is going to bounce back very strongly but we just can't say unless we can predict natural variability.

\section{Q: How do you feel about the development of climate models?}

Climate models have been on such a consistent track for the last 20, 30 years that it is hard to imagine them changing significantly. Basic theory and energy balance still plays a legitimate role, because it keeps reminding people that despite the complexity of the system there are some responses that are almost linear with respect to forcing, and we have to understand why this is so because it is not obvious. Take the example of the ideal gas law. Sometimes it seems like climate scientists want to solve the ideal gas law by integrating the interactions between every single atom in a box of gas. But of course the alternative way of doing it is to use the $\mathrm{pV}=\mathrm{nRT}$ relationship to calculate the pressure difference. I think we need to keep going back to these basic concepts like energy balance and realize that they have a great deal to offer.

\section{Q: You traveled around the world in the Royal Navy, did this experience have any bearing on your later scientific career?}

I learned many things there, among them one worth sharing with students in particular. I was teaching lower level college classes on navy ships for the Western Pacific fleet to students that would come on their own time to take courses. I really came to respect these students and learned that it is not how smart you are, but how much you care if you are going to get an education. That stuck with me forever.

\section{REFERENCES}

Crowley TJ, North GR (1991) Palaeoclimatology. Oxford University Press, 339pp

Crowley TJ (2000) Science 289: 270-277

Hyde WT et al. (2000) Nature 405: 425-429

Crowley TJ et al. (2014) Earth's Future 2: 281-294 